\title{
Emission Spectra of Crystal Phosphor $\mathrm{BaCl}_{2}-\mathrm{Pb}$
}

\author{
Veneta Tabakova \\ Institute for Foreign Students, Sofia, Bulgaria \\ Kyncho Kynev \\ Chemistry Department, Sofia University, Bulgaria \\ Z. Naturforsch. 35 a, 308-311 (1980) ; received December 24, 1979

\begin{abstract}
Emission spectra of $\mathrm{Pb}^{2+}$ centres in barium chloride single crystals have been studied between
\end{abstract} \\ 4 and $300 \mathrm{~K}$ by excitation with different wave lengths. Excitation spectra at $300 \mathrm{~K}$ have also been \\ obtained by measuring the emission in the maxima of the shortwave and longwave bands. The \\ results allow to conclude that the high energy emission band is due to the transition $\left|{ }^{3} \mathrm{~T}_{1 \mathrm{u}}\right\rangle$ \\ $\rightarrow\left|{ }^{1} \mathrm{~A}_{1 \mathrm{~g}}\right\rangle$ in the activator ion. The more effective excitation of the low energy emission band ob- \\ served in the shortwave region of the absorption spectrum and the complex nature of both bands \\ are discussed.
}

\section{Introduction}

It is known that in the emission spectra of lead doped alkali halides two bands are present which can be excited in the " $A$ " absorption band. The high energy emission band is connected in Ref. $[1-6]$ with the transition $\left|{ }^{3} \mathrm{P}_{1}\right\rangle \rightarrow\left|{ }^{1} \mathrm{~S}_{0}\right\rangle$ in dipole centres $\left(\mathrm{Pb}^{2+}-\mathrm{V}_{\mathrm{k}}\right)$ which are formed at low activator concentration and quenching of the samples studied. With respect to the origin of the low energy band there are different opinions. In an earlier work it has been ascribed to the transition $\left|{ }^{3} \mathrm{P}_{0}\right\rangle \rightarrow\left|{ }^{1} \mathrm{~S}_{0}\right\rangle$ [7], and later [5] to the transition $\left|{ }^{3} \mathrm{P}_{1}\right\rangle \rightarrow\left|{ }^{1} \mathrm{~S}_{0}\right\rangle$. According to newer investigations of Trinkler [9] "A" luminescence of the lead-doped alkali halides is due to transitions from two types of Jahn Teller emitting minima of the $\left|{ }^{3} \mathrm{P}_{1}\right\rangle$ state. Marculescu et al. [10] suppose that there is a resonant energy transfer between lead centres, and they connect the low energy emission band with the transition $\mu\left|{ }^{1} \mathrm{P}_{1}\right\rangle$ $+v\left|{ }^{3} \mathrm{P}_{1}\right\rangle \rightarrow\left|{ }^{1} \mathrm{~S}_{0}\right\rangle$.

Studies of $\mathrm{Pb}$ as activator in alkaline earth chlorides have been carried out on sublimated phosphors [11] as well as on polycrystalline $\mathrm{BaCl}_{2}$ samples with $5 \mathrm{~mol} \% \mathrm{PbCl}_{2}$ [12]. Investigations on monocrystals have been performed so far only on $\mathrm{Pb}$-doped strontium cloride [13].

\section{Experimental Procedure and Results}

The preparation of phosphors has been described in a previous work [14]. The emission and ex-

Reprint request to Dr. V. Tabakova, Institute for Foreign Students, Sofia, Bulgaria. citation spectra were measured by means of a luminescence accessory Cary 1442, an optical metal cryostat, a Bausch and Lomb Monochromator together with a deuterium lamp and a photomultiplier EMI 6256.

Figure 1 shows the emission spectra from excitation with $257 \mathrm{~nm}$ light in the most intensive longwave absorption band at $4 \mathrm{~K}, 77 \mathrm{~K}$, and $300 \mathrm{~K}$. Just as with the alkali halides, two bands appear. Their spectral positions and halfwidths are given in Table 1 .

The small halfwidth of the high energy band at $4 \mathrm{~K}$ allows to suppose that it is a single band. In accordance with this are the results given in Figure 2. But at $300 \mathrm{~K}$ this band is superposed by a shorterwave band in the region $295-305 \mathrm{~nm}$ curve 3, Figure 1.

The longwave band is also complicated, and this is manifested not only at $300 \mathrm{~K}$ but even clearer at $4 \mathrm{~K}$. It is possible that at $4 \mathrm{~K}$ the longwave shift is mainly due to the presence of a longwave component of this band. The deformation of curves $1^{\prime}$ and $2^{\prime}$ in the region of $450-470 \mathrm{~nm}$ indicates a superposition of one more lonwave component in this region. Thus the longwave band in the spectrum is probably composed of 3 bands.

The intensity of the bands at 310 and $403 \mathrm{~nm}$ increases when the temperature goes down, and increase of the shortwave band is even higher. While at $300 \mathrm{~K}$ the longwave band is predominant, at $4 \mathrm{~K}$ it is about 40 times weaker than the shortwave band.

Figure 3 shows emission spectra at $4 \mathrm{~K}$ obtained by excitation in different absorption bands. The

0340-4811 / $80 / 0300-0308 \$ 01.00 / 0$. - Please order a reprint rather than making your own copy. 


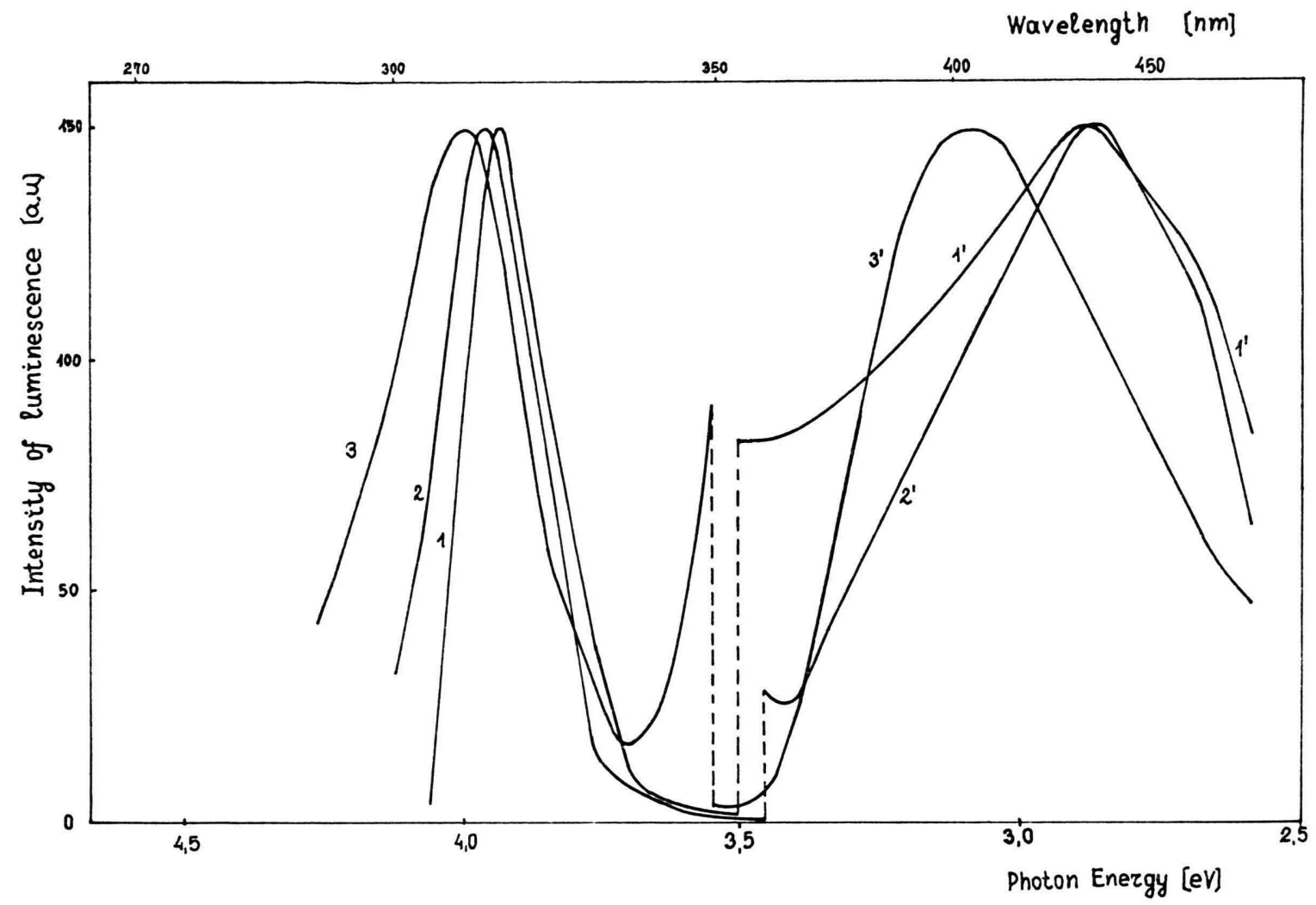

Fig. 1. Emission spectra by excitation with $257 \mathrm{~nm}$ at: $1,1^{\prime}-4 \mathrm{~K} ; 2,2^{\prime}-77 \mathrm{~K} ; 3,3^{\prime}-300 \mathrm{~K}$.

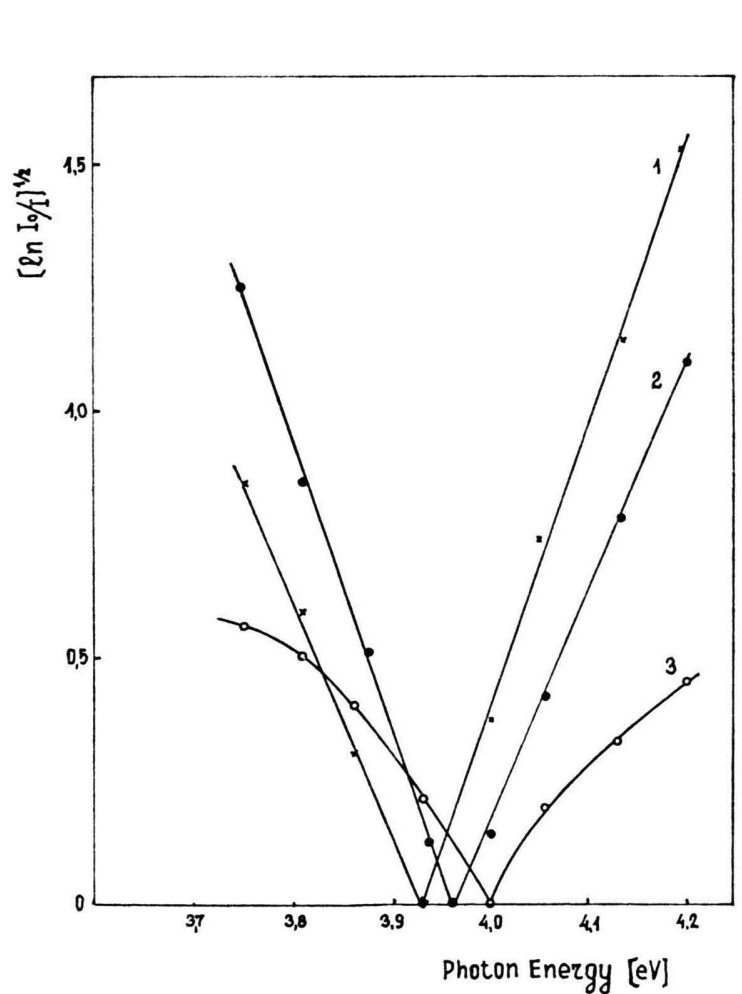

Fig. 2. Plot of $\left(\ln \mathrm{I}_{0} / \mathrm{I}\right)^{\frac{1}{2}}$ v.s. photon energy for the $315 \mathrm{~nm}$ emission band by excitation with $257 \mathrm{~nm}: 1-4 \mathrm{~K} ; 2-77 \mathrm{~K}$; $3-300 \mathrm{~K} . I_{0}=$ intensity in band maximum.

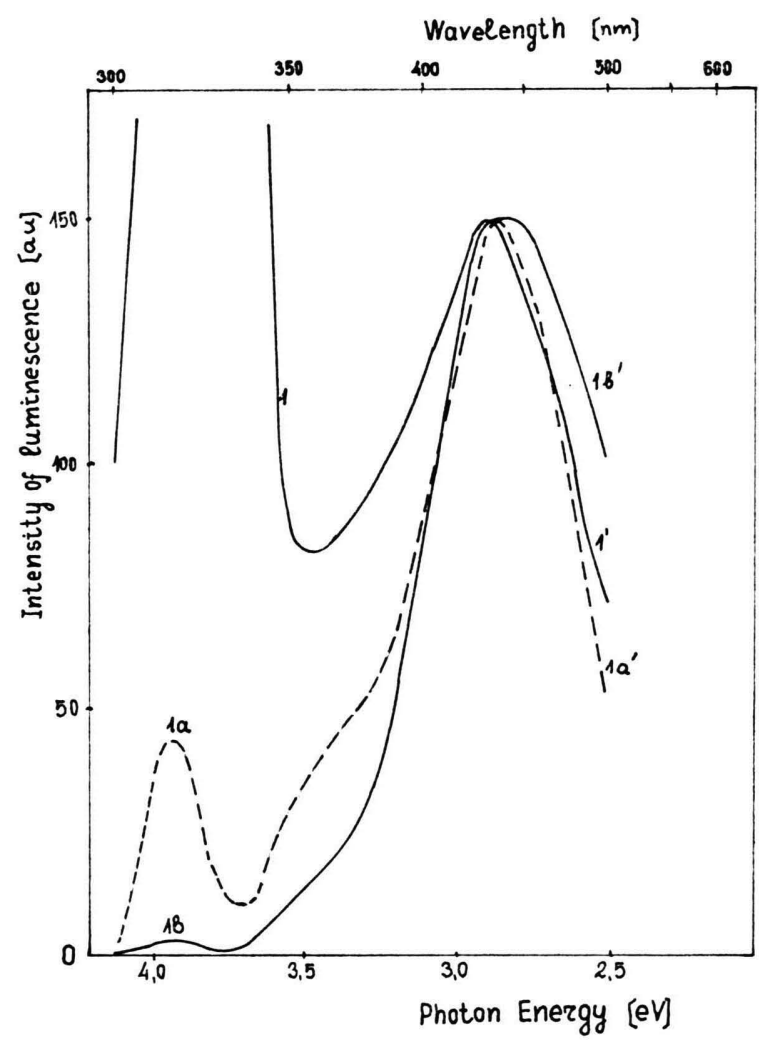

Fig. 3. Emission spectra obtained by excitation with: $257 \mathrm{~nm}$ $-1,1^{\prime} ; 235 \mathrm{~nm}-1 \mathrm{a}, 1 \mathrm{a}^{\prime} ; 215 \mathrm{~nm}-1 \mathrm{~b}, 1 \mathrm{~b}^{\prime}$. 
Table 1.

\begin{tabular}{rllllll}
\hline & \multicolumn{3}{l}{ Shortwave band } & & & \multicolumn{2}{l}{ Longwave band } \\
\cline { 2 - 4 } & Peak position & Halfwidth & Intensity & & Peak position & Intensity \\
\hline $47 \mathrm{~K}$ & $315 \mathrm{~nm}-3.93 \mathrm{eV}$ & $0.20 \mathrm{eV}$ & 3000 & & $431 \mathrm{~nm}-2.87 \mathrm{eV}$ & 70 \\
$300 \mathrm{~K}$ & $313 \mathrm{~nm}-3.96 \mathrm{eV}$ & $0.23 \mathrm{eV}$ & 3000 & & $435 \mathrm{~nm}-2.85 \mathrm{eV}$ & 50 \\
& $310 \mathrm{~nm}-4.00 \mathrm{eV}$ & $0.30 \mathrm{eV}$ & 1.7 & & $403 \mathrm{~nm}-3.07 \mathrm{eV}$ & 40 \\
\hline
\end{tabular}

excitation in the most shortwave absorption band $(215 \mathrm{~nm})$ leads to the appearance of the longwave emission band (curve $1 \mathrm{~b}^{\prime}$ ) of highest intensity. It can also be seen that in the region $350-370 \mathrm{~nm}$ a band appears which is most intensive by exciting at $235 \mathrm{~nm}$.

Figure 4 presents the excitation spectra obtained in measuring the emission at $400 \mathrm{~nm}$ (curve $4^{\prime}$ ) and at $310 \mathrm{~nm}$ (curve 4). As it can be seen from curve $4^{\prime}$, the longwave emission ( $\left(3^{\prime}\right)$ can be excited not only in the region $257 \mathrm{~nm}$ but also with a great quantum yield in the region $200-240 \mathrm{~nm}$. The maxima in the excitation spectrum $4^{\prime}$ at $215 \mathrm{~nm}$ and $240 \mathrm{~nm}$ correspond to the absorption maxima at $214 \mathrm{~nm}$ and $235 \mathrm{~nm}$. These absorption bands are only spurious at $300 \mathrm{~K}$ (curve 5 ), but they are well defined at $4 \mathrm{~K}$ [14]. The comparison of curve 4 and $4^{\prime}$ shows that in the region $300-350 \mathrm{~nm}$ the longwave band $3^{\prime}$ can be better excited than the shortwave band 3 .

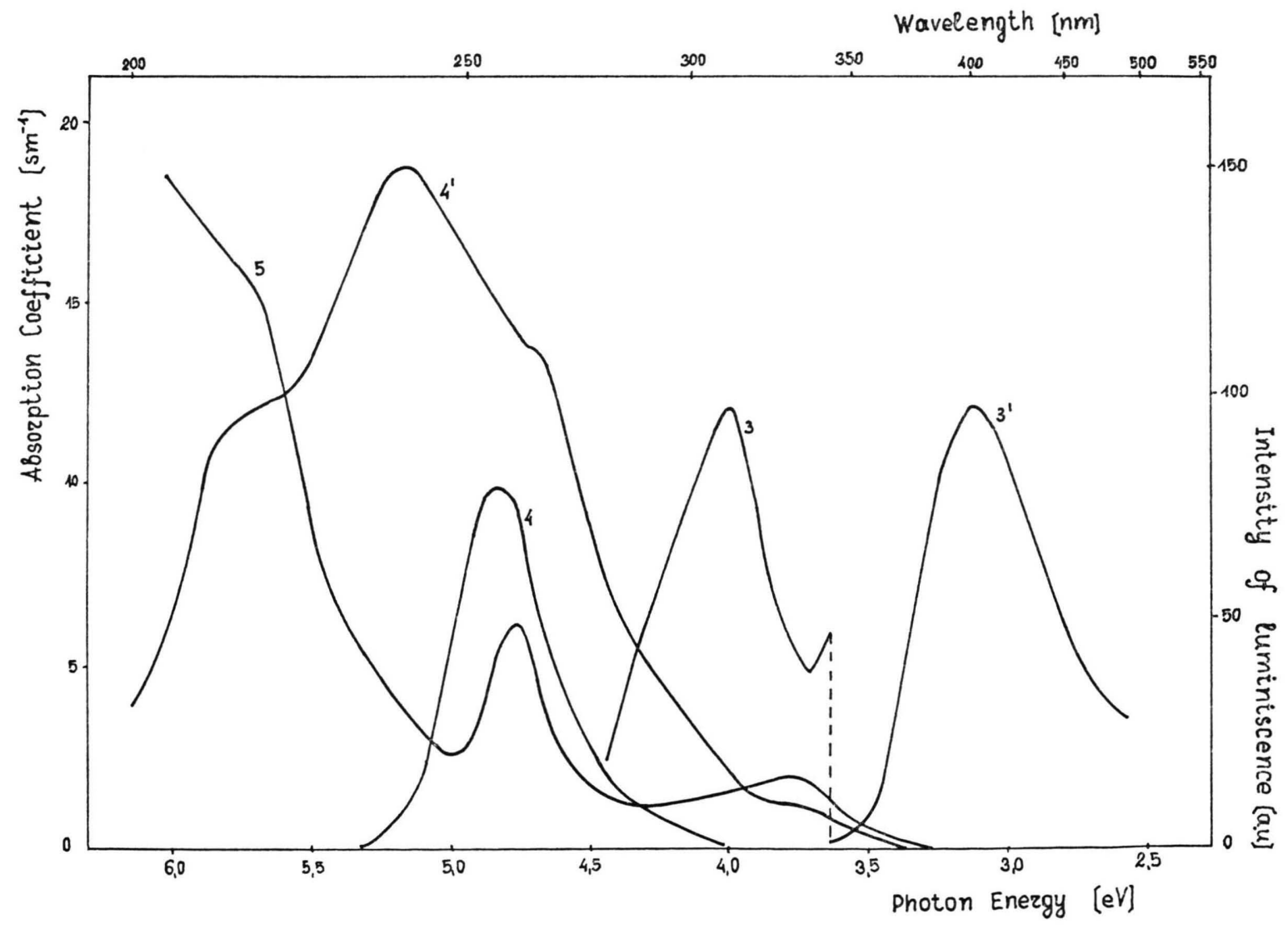

Fig. 4. Absorption, excitation and emission spectra at $300 \mathrm{~K}: 3,3^{\prime}-$ emission spectrum by excitation with $257 \mathrm{~nm} ; 4,4^{\prime}-$ excitation spectra for $403 \mathrm{~nm}$ and $310 \mathrm{~nm}$ emission bands; 5 - absorption spectrum. 


\section{Discussion}

The data on the dependance of the emission spectrum on the wave length of the exciting light as well as on the excitation and absorption spectra show that the high energy emission band at $310 \mathrm{~nm}$ should be ascribed to the transition $\left|{ }^{3} \mathrm{~T}_{1 \mathrm{u}}\right\rangle \rightarrow\left|{ }^{1} \mathrm{~A}_{1 \mathrm{~g}}\right\rangle$ in the activator ion.

The more effective excitation of the longwave band in the shorterwave region of the absorption spectrum can be explained by the assumption that the Stokes shift between the absorption and emission bands which are due to the transitions $\left|{ }^{1} \mathrm{~A}_{1 \mathrm{~g}}\right\rangle$ $\rightleftarrows\left|{ }^{1} \mathrm{~T}_{1 \mathrm{u}}\right\rangle$ is greater than the Stokes shift for

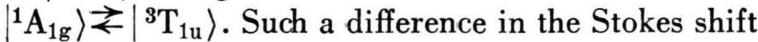
can be realized by an appropriate position of the potential curves corresponding to the $\left|{ }^{3} \mathrm{~T}_{1 \mathrm{u}}\right\rangle$ and $\left|{ }^{1} \mathrm{~T}_{1 \mathrm{u}}\right\rangle$ states.

The complex nature of the shortwave and longwave bands is probably a result of the low sym-

[1] Y. Kaifu, J. Phys. Soc. Japan 16, 1605 (1961).

[2] N. E. Lushchik, Tr. Inst. Fis. i Astron. Akad. Nauk Est. SSR 7, 119 (1958).

[3] P. Koeze and J. Volger, Physica 37, 467 (1967).

[4] J. S. Dryden, G. G. Harvey, J. Phys. C: Solid St. Phys. 2, 603 (1969).

[5] S. G. Zazubovich and T. A. Kuketaev, Tr. Inst. Fis. i Astr. Akad. Nauk Est. SSR 31, 190 (1966).

[6] A. Fukuda, Sh. Makishima, T. Mabuchi, and R. Onaka, J. Phys. Chem. Solids 28, 1763 (1967).

[7] M. F. Trinkler, Radiazonnaj Fisika III, Riga 1965, 133. metry of the centre determined by the low symmetry of the rhombic $\mathrm{BaCl}_{2}$. This leads to splitting of the $\left|{ }^{1} \mathrm{~T}_{1 \mathrm{u}}\right\rangle$ and $\left|{ }^{3} \mathrm{~T}_{1 \mathrm{u}}\right\rangle$ states, which creates the possibility for several radiative transitions especially at low temperatures.

The comparison of our results with those of Bettinali et al. shows that there is a good coincidence in the positions of the spectral bands at $310 \mathrm{~nm}$ and $403 \mathrm{~nm}$. The band at $350 \mathrm{~nm}$ is well expressed in the polycrystalline samples but in our case it only causes a deformation of the spectral curve at 340 $380 \mathrm{~nm}$. Probably this band is formed at the higher concentrations of the activator $(5 \mathrm{~mol} \%)$ in the polycrystalline samples studied [12].

\section{Acknowledgement}

One of authors (V.T.) is grateful to the DAAD for enabeling her to work at the Physics Institute of the University of Münster, Germany.

[8] M. F. Trinkler, L. E. Trinkler, A. E. Kalnin, Izv Akad. Nauk Latv. SSR, Ser. Fis. Techn. Nauk 3, 15 (1978).

[9] M. F. Trinkler, Optika Spektrosk. 46, 91 (1979).

[10] L. Mărculescu and G. Ghita, Phys. St. Sol. (b) 75, 375 (1976).

[11] A. F. Malisheva, Tr. Inst. Fis. i Astron. Akad. Nauk Est. SSR 10, 111 (1960).

[12] C. Bettinali and G. Ferraresso, Z. Phys. Chem. (NF) 67, 1 (1969).

[13] V. Vishnevskij et al., Ukr. Fis. J. 21, 20 (1976).

[14] V. Tabakova and K. Kynev, in press. 